\title{
A We Need a New International Norm: Eradicating the Gender Citation Gap
}

\section{Amanda Murdie}

Editor-in-Chief, International Studies Review, Dean Rusk Scholar of International Relations and Professor of International Affairs, Department of International Affairs, School of Public and International Affairs, University of Georgia, Athens, GA 30602, USA.Email: murdie@uga.edu

Citations not only convey importance in academia, but they also matter for a scholar's bottom line. As scholars, we want our work to be impactful to the broader discipline and to inform the future work of our peers and students. We also want to have successful careers, with many opportunities for advancement. Unfortunately, as Dion, Sumner, and Mitchell (2018) (hereafter DSM) convincingly show, there is a gender citation gap in many top social science journals. ${ }^{1}$ Even when gender diversity increases, women are still more likely than mixed-gender or men-only teams to cite women's work. These citation patterns are troubling. At the individual level, fewer citations can harm promotion chances; it can limit a scholar's career prospects. At the collective level, when women are not cited at the same rates as their colleagues, scientific advancement may be stalled as we fail to incorporate the ideas and insights from the full corpus of available scholarship. Women's work-even work that makes it through the grueling peer-review process at top journals like Political Analysis-may be less likely to inform future discovery.

In light of DSM's findings, it is clear that we all must work to make the eradication of the gender citation gap a reality. How do we do this? I suggest that the process to end the gender citation gap can be informed by the international relations' scholarship on how advocates and entrepreneurs establish new international norms. Like the eradication of foot binding or the spread of universal suffrage, eradicating the gender citation gap will require the establishment of a new norm against biased citation practices. Scholars in international relations have long had a thorough understanding of how new ideas become broadly accepted expectations of behavior worldwide (Florini 1996; Finnemore and Sikkink 1998). In no small way, we must draw on this scholarship as we seek to successfully change citation practices in the academy.

Let me briefly summarize what we know about how international norms develop. Established international norms like universal suffrage do not fall from the sky; instead, actors first must persuade others that there is an issue or problem worth addressing. These "norm entrepreneurs" must frame the issue as one that needs more attention (Finnemore and Sikkink 1998, 897). If advocates are successful in persuading a "critical mass" of actors (states or individuals) of the new norm, the movement can reach a "tipping point" where others quickly recognize the problem and strategically adopt the rhetoric of the new norm in order to fit in with their peers (Finnemore and Sikkink 1998, 901). Finally, as time progresses after this tipping point, the norm can become internalized, so accepted that "conformance with the norm" is "almost automatic" (Finnemore and Sikkink 1998, 904).

DSM are norm entrepreneurs. As such, they first must convince us that a problem exists. Using a variety of modeling approaches, their work shows that women are undercited across journals with dramatically different proportions of women authors, even though the problem is most pervasive in journals where there are lower proportions of women authors. This problem persists when DSM

Jeff Gill

(C) The Author(s) 2018. Published by Cambridge University Press on behalf of the Society for Political Methodology.
1 Much of the literature in this area assumes gender is binary; it is not. Unfortunately, this letter does not address gender as a spectrum. As work in this area progresses, hopefully we can start to understand how gender as a nonbinary concept enters into citation patterns. 
focus on citations to mixed-gender teams as well as to women-only work. Even more troubling, DSM do not find that women are being more cited over time.

Is this enough evidence to convince us that a problem exists? I think so. In addition to their analysis, DSM review previous scholarship that found a gender citation gap in other fields. They also highlight the myriad ways that citations matter for a scholar's career advancement. Women's careers are being harmed by the gender citation gap. The gap goes against long-held expectations that the academy values ideas and insights more than the personal characteristics of the source of these ideas.

Where do we go from here? I think there are three "Ss" that we as a discipline need to address to get us to the next stages in the development of an international norm eradicating the gender citation gap. First, we need increased active and passive socialization. Education about the existence of the problem is the first step. Scholarship on gender in academia needs to become required reading for graduate professionalization seminars. Editors can help increase awareness of the gender citation gap by including this information on their style sheets or submission guidelines. After reading DSM's piece, I added this information to the submission guidelines of the journal that I currently edit.

Socialization should also include the encouragement of women-led teams. Although DSM find somewhat similar results when looking at mixed-gender teams, in all journals sampled except for Politics and Gender, their results are slightly less problematic when looking at citations to mixedgender or women-only references in comparison to men-only teams (Figure A3). Perhaps womenled teams can draw attention to the implicit biases contributing to the gender citation gap. Further, as coauthorship has increased over time in political science and other social sciences, encouraging women to coauthor and lead mixed-gender teams may help passively socialize individuals against the gender citation gap (Henriksen 2016).

Socialization takes time; international norms typically do not become entrenched in a decade. The DSM 2007-2016 examination needs to be extended. By looking further back in history, we could examine whether the percentage of women in the author's PhD granting and home departments influence citation patterns. It could be that a critical mass of women in the department where the author was socialized during his or her PhD matters for overcoming the citation gap. Similarly, a critical mass of women in a scholar's current department may help in overcoming the "Matilda effect" (women's work being less valued) discussed in DSM.

Work that extends DSM in the future could also help us assess whether socialization efforts (Visions in Methodology, Journeys, etc.) aimed at limiting the leaky pipeline for women academics help in closing the gender gap. There is increased attention to the lack of self-citations by women scholars. This attention may help encourage self-citation, ultimately improving the visibility of scholarship by women.

Socialization efforts will require us as a discipline to have tough discussions about what closing the gender citation gap really looks like. Do we want citation percentages to be 50-50? Or, do we want them equal to the percentage of women-authored scholarship in the journal, field, or discipline? Do we want to look at current percentages of women in graduate school or percentages from some time in the past? When will we know that the gap is closed? Similar questions are being addressed in the advocacy movement around racial bias in criminal justice, an altogether much more troubling problem that also needs to be eradicated internationally, and in advocacy to end gender bias in the tech industry. These questions will require us to think about gendered patterns of topic choice and the processes that limit women's involvement and retention in certain subdisciplines. For example, if women make up only $37 \%$ of the International Studies Association's International Security Studies section, can we reasonably expect women to make up $50 \%$ of the 
citations in this area? ${ }^{2}$ Should scarce resources be first devoted to address the citation gap or to address the lack of women studying the topic in the first place? Can resources be used for both problems simultaneously? Like in other areas of advocacy for new international norms, these questions have both moral and practical implications.

Second, socialization takes time. In the meantime, I think we need more space. One potential omitted factor in DSM is the length of an article. Could the word limit of various journals over time influence the gender citation gap? Of the journals that DSM sampled, all except Sociological Methods \& Research (SMR) have word or page limits listed on their webpages. Email correspondence with SMR confirmed that they do not have a preset word limit. Is this somehow linked to the fact that SMR was the methodology journal DSM found to have the highest percentage of citations to women? Once we account for differences in diversity across disciplines, the gender citation gap could possibly be alleviated by less rigid word or page limits. As scholars work to shorten papers for final submission, it is likely that they eliminate references seen as nonessential. Implicit gender bias could influence which references are viewed in this way. Journals could even conduct experiments on this topic; if some authors are assigned a larger word limit than others, does the treatment group cite women more?

Finally, once socialization has occurred and space has been provided, I think we need to shame papers that overwhelmingly contribute to the gender gap. By "shaming," I am referring to the process of strategically calling out norm breakers for their deviant behavior. My own work in international relations shows that shaming can change state and individual behavior in certain situations (Murdie 2014). By applying the tools DSM used to probabilistically identify gender, we could all identify papers that have particularly egregious gender citation gaps in our substantive area. As an editor, I am now providing gender citation percentages to our authors. This information from a journal editor may be enough to encourage authors to think more critically about their citation patterns. We could also single out papers that significantly deviate from discipline or journal standards. Conversely, we could praise authors whose gender citation patterns limit the gap.

In short, DSM provide important evidence of a problem. However, being aware of the problem is not enough. For a fully internalized international norm to develop against the gender citation gap, we need to build a critical mass of scholars who understand the problem and are working to alleviate it. We should allow more space for authors to add missing citations and, if needed, shame authors who deviate from agreed-to best practices. By socializing, providing space, and shaming nonadopters, perhaps we can eliminate the gender gap and help improve scientific discovery.

\section{References}

Finnemore, Martha, and Kathryn Sikkink. 1998. International norm dynamics and political change. International Organization 52(4):887-917.

Florini, Ann. 1996. The evolution of international norms. International Studies Quarterly 40(3):363-389.

Henriksen, Dorte. 2016. The rise in co-authorship in the social sciences (1980-2013). Scientometrics 107(2):455-476.

Murdie, Amanda. 2014. Help or harm: The human security effects of international NGOs. Stanford, CA: Stanford University Press.

2 http://www.isanet.org/ISA/About-ISA/Data/Gender. 